\title{
Retroelements: molecular features and implications for disease
}

\author{
Yi-Deun Jung ${ }^{\dagger}$, Kung Ahn ${ }^{\dagger}$, Yun-Ji Kim, Jin-Han Bae, \\ Ja-Rang Lee and Heui-Soo Kim* \\ Department of Biological Sciences, College of Natural Sciences, \\ Pusan National University, Busan 609-735, Republic of Korea
}

(Received 29 June 2012, accepted 9 January 2013)

\begin{abstract}
Eukaryotic genomes comprise numerous retroelements that have a major impact on the structure and regulation of gene function. Retroelements are regulated by epigenetic controls, and they generate multiple miRNAs that are involved in the induction and progression of genomic instability. Elucidation of the biological roles of retroelements deserves continuous investigation to better understand their evolutionary features and implications for disease.
\end{abstract}

Key words: disease, epigenetic variation, miRNAs, radiation, retroelements

\section{INTRODUCTION}

Retroelements cause genomic instability, change the structure of the host genome by retrotransposition or by generating chromosomal rearrangements through homologous recombination (HR). This is attributed to their ability to mobilize, abundance, and high degree of sequence similarity (Kazazian, 2004; Biémont and Vieira, 2006; Britten, 2006). High copy numbers of retroelements could generate genomic instability, which results from changes in genomic structure and gene function by rearrangements, translocations, insertions, and deletions (Deininger and Batzer, 1999; Kolomietz et al., 2002; Bailey et al., 2003; Cordaux and Batzer, 2009). Retroelement alterations induced by epigenetic control could interfere with host gene expression programs (Bird, 2002; Slotkin and Martienssen, 2007; Suzuki and Bird, 2008; Macfarlan et al., 2011; Karimi et al., 2011). These retroelements could induce diseases such as cancer (Cruickshanks and Tufarelli, 2009; Richards et al., 2009). High copy numbers of retroelements provide a mechanism for the generation of multiple miRNA genes with homologous target sites interspersed in the human genome (Smalheiser and Torvik, 2005; Piriyapongsa et al., 2007). Radiationinduced overexpression of retroelements provides the driving force for accumulating genetic alterations responsible for multistep carcinogenesis (Belgnaoui et al., 2006; Farkash et al., 2006; Arruda et al., 2008). Retroelements are responsible for genetic variation and gene regulation through various mechanisms, which are critical factors in the generation of genetic diseases during hominid radia-

\footnotetext{
Edited by Hidenori Nishihara

* Corresponding author. E-mail: khs307@pusan.ac.kr

$\dagger$ These authors contributed equally to this work
}

tion.

A high copy number of retroelements gives rise to several opportunities for generating miRNAs, which are involved in gene regulation. Elucidation of the relationship between the retroelements and miRNAs is very important for understanding post-transcriptional regulatory processes. Retroelements regulated by epigenetic control could also facilitate the regulation of host genes. Understanding epigenetic control of retroelements would thus provide important information regarding tissuespecific promoter activity, developmental phenotypes, and various human diseases. Thus, retroelements are very important factors that influence neighboring gene regulation, structural change, phenotype, evolutionary radiation, and various diseases.

\section{GENOMIC INSTABILITY INDUCED BY RETROELEMENTS}

Retroelements can generate genomic instability, resulting from changes in genomic structure and gene function, through rearrangements, translocations, insertions, and deletions (Kazazian, 2004; Biémont and Vieira, 2006; Kim et al., 2010; Ha et al., 2011; Hong et al., 2011). Retroelements can modulate gene expression by serving as promoters, enhancers, and silencers (Mager et al., 1999; Sharan et al., 1999; Britten, 2006; Mätlik et al., 2006). They often change the structure of their host's genome by retrotransposition and by chromosomal rearrangements through $\mathrm{HR}$ due to their ability to mobilize and their abundance and high sequence similarity (Cordaux and Batzer, 2009; Lee et al., 2009a; Romanish et al., 2010). In the human genome, most human endogenous retroviruses (HERVs) are present as solitary long terminal repeat (LTR) structures, which are formed 
through HR events between LTRs of full-length HERVs (Hughes and Coffin, 2004; Mayer et al., 2005; Lee et al., 2009b). Human-specific LTRs are involved in the specific activation of functional genes, polyadenylation signals, splice sites, and as antisense regulators in embryonic and cancer tissues (Schulte et al., 2000; Kim et al., 2005; Ruda et al., 2004; Sin et al., 2006; Illarionova et al., 2007; Huh et al., 2008; Ahn et al., 2009). Retroelements may also function through $\mathrm{HR}$ and nonhomologous end joining (NHEJ) (Hughes and Coffin, 2001). NHEJ appears to be the main mechanism for the creation of translocations (Weinstock et al., 2006). Retroelement-mediated nonallelic HR translocations commonly occur by chance. Retroelements are found in the vicinity or within breakage points of chromosomal translocations (Kolomietz et al., 2002). To date, very few HERV-mediated recombinational events have been demonstrated in the human genome. A recombination event between HERV15 within the gene encoding azoospermia factor 1 (AZF1) causes large deletions and spermatogenic failure (Sun et al., 2000). The high copy number of retroelements results in genetic instability through deletion and duplication by HR. Further, the substrate can influence the outcomes of the repair of double strand breaks, which can result in chromosomal translocations (Cordaux and Batzer, 2009).

Insertional mutagenesis caused by retroelements is deleterious to the host and can result in genetic disorders (Hedges and Deininger, 2006). It is not only the major factor of genetic instability, but it can also result in muscular dystrophy or breast cancer (Miki et al., 1992; Ostertag and Kazazian, 2001b). Line-1 retroposons (L1s) can change the structure of the genome structure through reverse transcription or mobilizing sequences derived from their 3 ' flanks (Moran et al., 1999; Nelson et al., 1999; Kim et al., 2006). DNA recombinational events between non-allelic L1s can induce genomic rearrangement and disease (Moran et al., 1999; Lee et al.,
2008). Short interspersed nuclear elements (SINEs) are present in large copy numbers in the genome; they are short in length; and they cannot encode reverse transcriptase. Recombinational events are known to occur in leukemia and various diseases (Deininger and Batzer, 1999; Medstrand et al., 2001; Goodier and Kazazian, 2008).

Alu elements can convert genes through homologous sequence recombinational events (Kass et al., 1995; Roy et al., 2000; Lee et al., 2008). In the human genome, a large number of $A l u$ elements are present in the regions of segmental duplications. Alu elements not only cause duplications but also seem to contribute to deletion events (Bailey et al., 2003). In particular, human-specific Alu recombination-mediated deletion (ARMD) events results in the deletion of approximately 400 kilobases $(\mathrm{kb})$ of genomic sequence (Sen et al., 2006; Lee et al., 2009a). These Alu-related rearrangements lead to various recurrent genetic diseases (Walsh et al., 2006; Han et al., 2007). Taken together, the results of these studies indicate that retroelement sequences could have a significant impact on their hosts. Rearrangements, translocations, insertions, and deletions caused by retroelements could result in genome instability and interfere with host-gene expression programs (Table 1).

\section{RETROELEMENT ALTERATION BY EPIGENETIC CONTROL}

Generally, epigenetic control includes the following 2 processes: DNA methylation or histone modification of proteins that form nucleosomes. Several eukaryotes use these epigenetic mechanisms to inhibit the activity of retroelements. The correlation between retroelements and epigenetic modifications was first identified in plants and fungi (Slotkin and Martienssen, 2007; Suzuki and Bird, 2008), and later in mammals (Kano et al., 2007;

Table 1. Events of retroelement induced genome instability

\begin{tabular}{ccccc}
\hline \hline \multicolumn{1}{c}{ Events } & Genes & Elements & References \\
\hline \multirow{5}{*}{ Alteration } & MCJ & HERV & (Mätlik et al., 2006) \\
& ZBTB38 & SINE & (Kazazian, 2004) \\
\cline { 2 - 5 } & Translocation & EWSR1-ETV & SINE & (Onno et al., 1992) \\
\cline { 2 - 5 } & \multirow{2}{*}{ Recombination } & AZFa & HERV & (Hughes and Coffin, 2004) \\
& & BRCA1,2 & SINE & (Kim et al., 2006) \\
\cline { 2 - 5 } & Retroposition & APC & LINE, SINE & (Mayer et al., 2005) \\
\hline \multirow{3}{*}{ Function } & Promoter & KIAA1797, CLCN5, SLCO1A2 & LINE & (Hutchinson et al., 1993) \\
\cline { 2 - 5 } & Enhancer & ESR & SINE & (Bird, 2002) \\
\cline { 2 - 5 } & Suppressor & BRCA & SINE & (Slotkin and Martienssen, 2007) \\
\cline { 2 - 5 } & Polyadenylation & HHLA2, HHLA3 & HERV & (Kolomietz et al., 2002) \\
\hline
\end{tabular}


Cruickshanks and Tufarelli, 2009; Richards et al., 2009; Ichiyanagi et al., 2011).

In somatic and mature germ cells, retrotransposition and transcriptional activity of retroelements is predominantly suppressed by methylation and chromatin structure (Bird, 2002). Using this process, interactions between retroelements and their hosts are maintained in stable equilibrium (Schulz et al., 2006). Retroelements may be the original targets for epigenetic mechanisms, which have global impacts on the regulation of gene expression and genome organization. Well-documented changes in retroelements include DNA methylation of gene promoters. There are 1520 human genes that harbor transcription start sites, and they are annotated as retroelement boundaries (Huda et al., 2011). Long interspersed elements (LINEs) and SINEs that are present in promoter regions are frequently methylated in normal cells. However, hypomethylation of these elements can cause alternative transcription or tissue-specific expression (Cruickshanks and Tufarelli, 2009; Richards, 2009; Macaulay et al., 2011). In SINEs, dynamics and mode of SINEs methylation regulate transcription in their promoter regions (Ichiyanagi et al., 2011). LTR elements also contain promoter sequences and can function as alternative promoters for nearby cellular genes (Cohen et al., 2009). Their tissue-specific promoter activity is also affected by DNA methylation status (Reiss et al., 2007; Huh et al., 2008; Stengel et al., 2010; Cohen et al., 2011). Also, in genic regions, the correlation with intronic ERVs and DNA methylation status regulate gene expression (Kano et al., 2007; Li et al., 2012).

Further, histone modification influences the expression and promoter activity of retroelements (Ichiyanagi et al., 2011; Karimi et al., 2011; Macfarlan et al., 2012). In the promoter region, retroelements have different histone modifications, including 7 activating modifications (H3K4me2, H3K9ac, H3K4me3, H3K27me1, $\mathrm{H} 3 \mathrm{~K} 36 \mathrm{me}$, and H4K20me1) and a repressive modification (H3K27me3, H3K9me2, and H3K9me3) (Pauler et al., 2009; Matsui et al., 2010; Rowe et al., 2010; Carabana et al., 2011; Huda et al., 2011; Karimi et al., 2011; Teneng et al., 2011). A study on the epigenome of mouse embryonic stem cells demonstrates that there is an association between repressive histone modifications and different types of retroelements (Martens et al., 2005). A specific retroelement is linked to a dual epigenetic marker, which regulates its transcriptional activation (Brunmeir et al., 2010). Alu and LINE-1 elements are more highly expressed in human embryonic stem cells (hESCs) than in somatic tissues. Their expression in hESCs, particularly the expression of pluripotent genes, is due to epigenetic control (Macia et al., 2011). Histones modification of retroelements is known to occur in stem cells (Maksakova et al., 2009). The modification status appears to depend on the state of cellular differentiation in which modification of retroelements can be easily changed during the early developmental stage by the epigenetic reprogram (Maksakova et al., 2009). However, epigenetic features can vary, depending on the cell fate, conditions, stage of differentiation, and related disease. Whole of epigenetic status of retroelements could not present accuracy in Fig. 1 , however, epigenetic status of retroelements are similar to in principle with some exceptions. In ESC, epigenetic features are reprogrammed and their alteration tends to decrease their activity in somatic cells. Some retroelements could provide alternative splicing sites (Sverdlov,

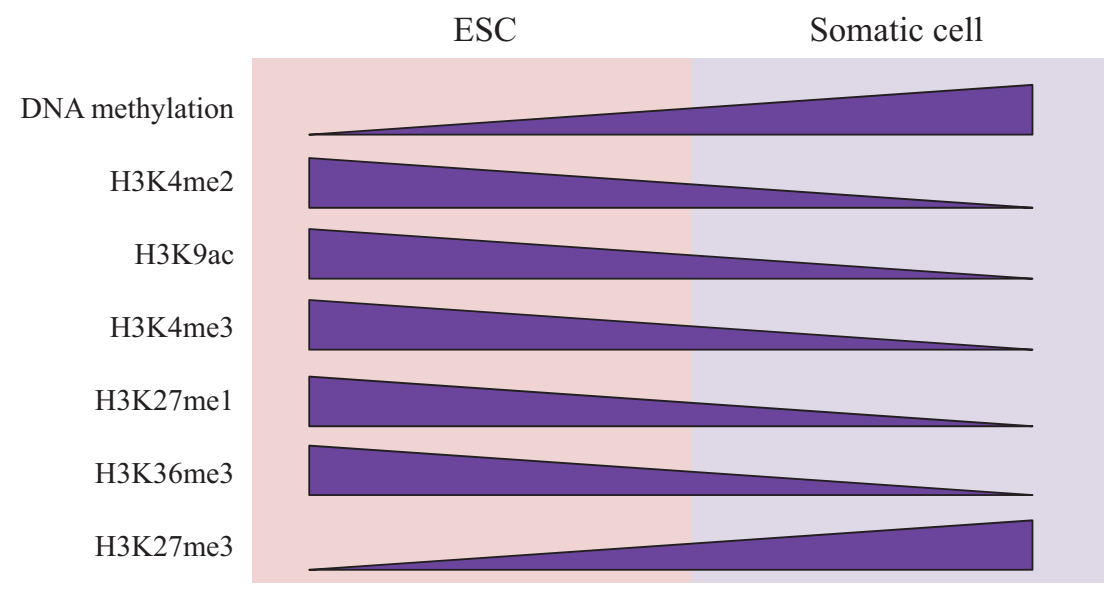

Fig. 1. General distribution pattern of cell type-specific epigenetic control directed by retroelements. Epigenetic features are mainly reprogrammed in the embryo stem cell. The correlations to retroelements tend to be more significant in embryo stem cells. However, in somatic cells, retroelements induce gene silencing, because they could affect the expression of human functional genes. Thus, epigenetic alternation of retroelements tends to decrease their activity in somatic cells. However, epigenetic features can vary, depending on the cell fate, conditions, stage of differentiation, and related disease. Thus, epigenetic features of retroelements are similar to in principle with some exceptions. 
2000). In identical genetic sequences, determination of alternative splicing sites may be regulated by epigenetic control (Luco et al., 2011).

Retroelements containing $\mathrm{CpG}$ sites are regulated by DNA methylation. In $A l u$ sequences, CpG sites are localized in the essential A and B boxes, and their methylation state prevents binding of Pol III cofactors (Kochanek et al., 1995). Repression of LINE-1 by methylation mediates methylcytosine-binding proteins MeCP2 and MBD2 (Steinhoff and Schulz, 2003). These processes show that DNA methylation directly interferes with their expression by binding to transcriptional activators. The influence of the effects of methylation on the expression of HERV genomes has been also reported (Walsh et al., 1998; Bourc'his and Bestor, 2004). However, some transcription factors that elicit gene expression in germ cells and some carcinomas have been identified (Schön et al., 2001; Wang-Johanning et al., 2003; Liang et al., 2010). It has also been reported that histone acetylation of LINE-1 is regulated by retinoblastoma proteins (MontoyaDurango et al., 2009).

The biological significance of retroelements is still unclear. However, development and cell fate determination is known to require a balance between genetic and epigenetic programs. Retroelements regulated by epigenetic control could facilitate the regulation of host genes. These retroelements could play an important role in the progression of several diseases or during the evolutionary dynamic process in speciation.

\section{miRNA FUNCTION AND RETROELEMENTS}

Retroelements play important roles at the transcriptional and post-transcriptional levels in the human genome. For example, a post-transcriptional gene silencing (PTGS) mechanism has been established for noncoding RNAs such as siRNA (small interfering RNA) and microRNAs (miRNAs), which are closely related to another class of non-coding RNA, known as small interfering RNAs, in terms of both biogenesis and regulatory function (Bartel, 2004). miRNAs are generally found in specific genomic loci, particularly in the intergenic regions, while siRNAs originate from within characterized sequences such as genes and retroelements (Hutvágner and Zamore, 2002; Bartel, 2004).

Evolution has generated multiple pathways to inhibit retrotransposition because of the deleterious nature of retroelement insertions and rearrangements. P-elementinduced wimpy testis (Piwi) proteins and repeat-associated small interfering RNAs (rasiRNAs) play a pivotal role in post-transcriptional silencing of genomic parasites. In Drosophila, a novel rasiRNA homologous to the antisense strand of retroelements prevents the detrimental retroelements of the gypsy endogenous retrovirus through the activities of RNAi and miRNA (Vagin et al., 2006;
Pélisson et al., 2007). The mammalian Piwi proteins, MIWI and MILI also regulate transcription and posttranslational silencing of retroelements in mouse germ cells (Aravin et al., 2007, 2008; Kuramochi-Miyagawa et al., 2008; De Fazio et al., 2011). Especially, DNA methylation of LINE1 elements is linked to Piwi proteins and piRNA amplification (Kuramochi-Miyagawa et al., 2008; De Fazio et al., 2011). Because of their tight association with Piwi proteins and their evolutionary conservation throughout the animal kingdom, rasiRNAs were renamed Piwi-interfering RNAs (piRNAs). According to the "pingpong" amplification model, sense-rasiRNAs result from the processing of long sense transcripts with the assistance of PIWI or Aubergine (Aub)-associated antisense, and sense rasiRNAs in complex with Ago3 guide the cleavage of antisense transcripts to produce additional antisense rasiRNAs (Brennecke et al., 2007; Gunawardane et al., 2007). Recent reports also indicate that the coevolution of retroelements with their host genomes led to the incorporation and integration of retroelements into complex genomic processes. For example, Alu elements are found in $>5 \%$ of all human $3^{\prime}$-UTRs (Yulug et al., 1995). Furtherore, B1-derived small RNAs regulated gene expression in mice has been reported (Ohnishi et al., 2012). New evidence provided by studies on the targeting of $A l u$ sequences by miRNAs suggests that $A l u$ sequences participate in the regulation of global gene expression (Daskalova et al., 2007). Thus, Alu elements residing in $3^{\prime}$-UTRs could function as mobile regulatory modules that supply binding sites for the regulation of miRNA expression.

The relationship between retroelements and miRNAs was discovered when a number of miRNA genes were derived from the sequences of retroelements (Matzke et al., 2004; Smalheiser and Torvik, 2005; Piriyapongsa et al., 2007). The high copy number and repetitive nature of retroelements could provide a mechanism for the generation of multiple miRNA genes with homologous target sites interspersed in the human genome. The insertion of LINE-2 elements into genomic sites appears to be one of the driving forces behind the creation of new miRNAs (Smalheiser and Torvik, 2005). Various repetitive sequences contribute to the production of miRNAs. In particular, retroelements such as LINEs and SINEs are present at high frequency in many repetitive sequences (Fig. 2). Transposition via an RNA intermediate of retroelements could represent an advantageous mechanism for the processing of miRNAs under conditions such as stress and irradiation. Thus, miRNAs derived from retroelements as well as DNA transposons could influence mRNA silencing by PTGS. They may provide an evolutionary connection between siRNAs and miRNAs. Thus, the wide distribution of retroelements could exert either harmful or beneficial effects on genomic stability or the host cell. In particular, retroelements present at a high 
copy number could play an important role in gene silencing within human cells and could have an enormous impact on the survival of individuals. Therefore, determining the relationship between retroelements and miRNAs is very important for understanding post-transcriptional regulatory processes.

\section{CHANGES IN THE STRUCTURE AND EXPRESSION OF RETROELEMENTS BY RADIATION}

Retroelements are a source of genome instability, and genotoxic stress promotes their activation. DNA lesions

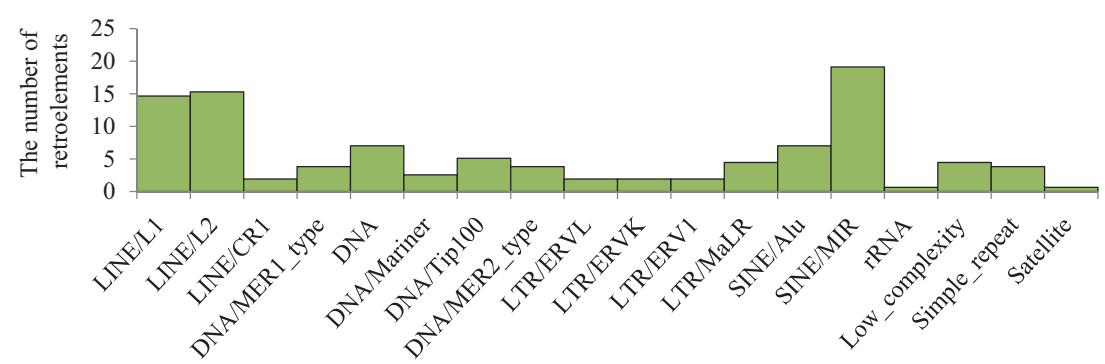

Fig. 2. Retroelement families contribute to human genomic miRNA sequences (human genome build: hg18). The $\mathrm{X}$-axis indicates retroelement families that contribute to miRNA sequences, and the Y-axis indicates the number of retroelements. Retroelements consisting of $>50 \%$ miRNA sequences were selected.

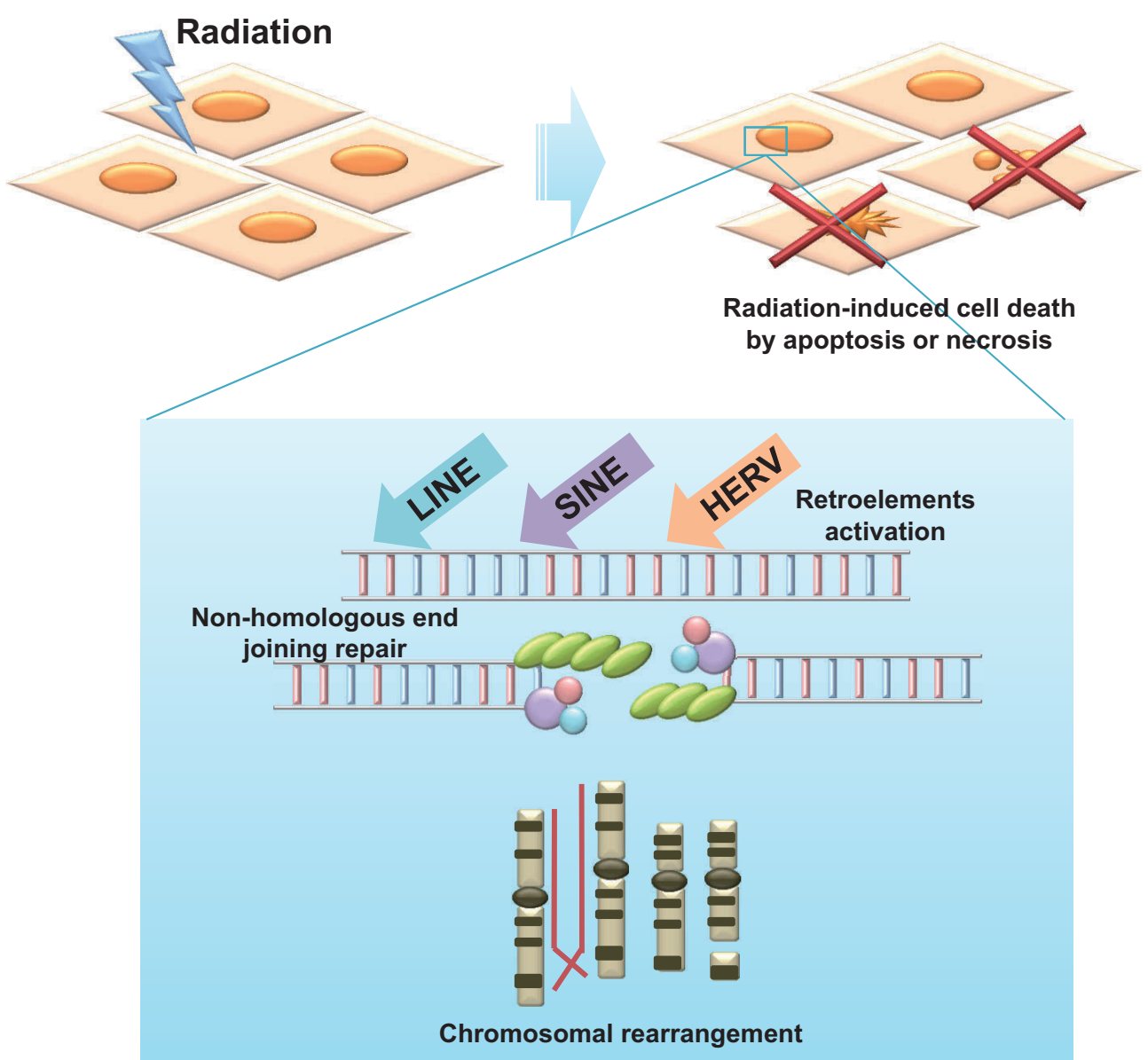

Fig. 3. Schematic representation of cell responses to radiation. Radiation induces double-strand breaks (DSBs), which cause the accumulation of mutations, and induce apoptosis, necrosis, and growth arrest. When DSBs are detected by the cell, a complex cascade of reactions is triggered, which immediately recruits repair factors and promotes non-homologous end joining repair. Various types of phenotypes are expressed in surviving cells. In particular, the radiation-induced activation of retroelements induces genomic instability via homologous recombination, duplication, deletion, and retrotransposition. These responses are the principal cytotoxic lesion induced by radiation and lesion leading to chromosomal rearrangements. 
are induced by various endogenous and exogenous genotoxic stressors such as replication fork collapse, virus infection, and exposure to ionizing radiation (Hoeijmaker, 2001). Radiation can induce DNA double-strand breaks (DSBs) through oxidative damage. After the induction of DSBs, NHEJ repair is activated (Jackson, 2002). These signaling pathways recruit DNA repair factors to DSBs, alter transcription, and may trigger significant damage, resulting in cell cycle arrest or even apoptosis. Various cellular events that occur secondary to DNA damage may affect the activation of retroelements (Fig. 3).

A wide variety of retroelements induces transcriptional activation caused by activation of the promoters of retroelements after exposure to ionizing radiation. Irradiation with ultraviolet light B (UVB) increases the promoter activity of the intracisternal A-particle (IAP) LTR in a dose- and time-dependent manner in D152 murine cells (Faure et al., 1996). The transcriptional activation and protein synthesis of retroelements results from activation of their promoter sequences. In particular, transcription of the pol genes of various HERV families is induced by UVB-irradiation of normal human primary epidermal keratinocytes and a keratinocyte cell line (Hohenadl et al., 1999). Moreover, overexpression of HERV-K rec and np9 is induced in normal human epidermal melanocytes and melanoma cell lines by UVC (Reiche et al., 2010).
Transcription of the most common human LINE element, $\mathrm{L} 1 \mathrm{Hs}$, is increased by promoter activation as well as that of the reverse transcriptase of LINE-1 after treatment with UV light (Morales et al., 2003 Banerjee et al., 2005). Upregulation of retroelements occurs in numerous types of cancers (Romanish et al., 2010). Thus, radiationinduced overexpression of retroelements provides the driving force for the accumulation of genetic alterations responsible for multistep carcinogenesis.

Radiation-induced transcriptional activation of retroelements supports the notion that radiation exposure results in global hypomethylation (Goetz et al., 2011). In fact, radiation-induced DNA hypomethylation of LINEs and SINEs has been reported previously (Aypar et al., 2011). DNA methylation of retroelements is an important host defense mechanism in mammals. Thus, a high degree of methylation of the promoters of retroelement promoters may result in increased stability of the genome by silencing the expression of retroelements (Yoder et al., 1997). Transcriptional activation of retroelements induced by hypomethylation contributes to genome instability. Thus, evidence indicates that the global loss of DNA methylation after radiation treatment is involved in carcinogenesis via reactivating latent retroelements, genomic instability, and activation of protooncogenes.

Table 2. Radiation induced genomic and epigenomic change of retroelements

\begin{tabular}{|c|c|c|c|c|}
\hline Radiation-induced change & Retroelements & Family & Irradiation amount & References \\
\hline \multirow{4}{*}{ Hypomethylation } & LINE-1 & LINE & \multirow{2}{*}{ X-ray 2.0 Gy, $\gamma$-ray $1.0 \mathrm{~Gy}$} & \multirow{2}{*}{ (Banerjee et al., 2005) } \\
\hline & Alu & SINE & & \\
\hline & LINE & SINE & X-ray 10,100 cGy, $\gamma$-ray & \\
\hline & Alu & LINE & $10,100 \mathrm{cGy}$ & (Reiche et al., 2010) \\
\hline \multirow{2}{*}{ Promoter Activation } & IAP & SINE & UV $1-50 \mathrm{~J} / \mathrm{m}^{2}$ & (Matzke et al., 2004) \\
\hline & LINE-1 & LINE & $\mathrm{UV} 10,20 \mathrm{~J} / \mathrm{m}^{2}$ & (Hohenadl et al., 1999) \\
\hline \multirow{10}{*}{$\begin{array}{l}\text { Transcriptional } \\
\text { Activation }\end{array}$} & HERV-K-T47D & & \multirow{8}{*}{ UVB $10,30 \mathrm{~mJ} / \mathrm{cm}^{2}$} & \multirow{8}{*}{ (Hoeijmaker, 2001) } \\
\hline & HERV-K & & & \\
\hline & HERV pol & & & \\
\hline & HERV-E & & & \\
\hline & HERV-L & ERV & & \\
\hline & ERV FRD & & & \\
\hline & ERV9-related & & & \\
\hline & HERV-H & & & \\
\hline & HERV-K & & UVC $10,30 \mathrm{~mJ} / \mathrm{cm}^{2}$ & (Jackson, 2002) \\
\hline & LINE-1 & LINE & $\begin{array}{c}\text { UVA+B (UVA, } 150-200 \mathrm{~J} / \mathrm{cm}^{2} \\
\text { and UVB, } 15-20 \mathrm{~J} / \mathrm{cm}^{2} \text { ) }\end{array}$ & (Hohenadl et al., 1999) \\
\hline \multirow{2}{*}{ Duplication } & HERV & ERV & Radiateion accident & (Goetz et al., 2011) \\
\hline & IAP & ERV & X-ray 3 Gy & (Aypar et al., 2011) \\
\hline \multirow{2}{*}{ Retrotransposition } & LINE-1 & LINE & $\gamma$-ray 2,4 Gy & (Yoder et al., 1997) \\
\hline & LINE-1 & LINE & $\gamma$-ray 5 Gy & (Tanaka and Ishihara, 1995) \\
\hline
\end{tabular}


Importantly, activation of retroelements by radiation induces genomic instability, including genomic rearrangements, such as deletions, insertions, and duplications (Tanaka and Ishihaha, 1995; Arruda et al., 2008). L1 mobilization increases in $\gamma$-irradiated cells, and most L1 insertions in irradiated cells are known to undergo endonuclease-dependent L1 retrotransposition (Farkash et al., 2006). Therefore, L1 retrotransposition is one of the main reasons that account for radiation-induced genomic instability. Moreover, L1 retrotransposition creates an apparent synergistic interaction between L1 activation and radiation by enhancing radiation lethality through the induction of apoptosis (Belgnaoui et al., 2006). Several studies have demonstrated that radiation-induced genomic instability is generated from genomic rearrangement and retrotransposition mediated by the activation of retroelements (Table 2).

\section{HUMAN DISEASES AND RETROELEMENTS}

Some retroelements are transcriptionally active and move around the genome by retrotransposition, resulting in insertional mutagenesis, changes in genome structure, and changes in the expression of neighboring genes
(Druker and Whitelaw, 2004). Eventually, these events could result in the progression of human diseases (Table 3). LINE elements can cause large-scale genomic alterations that are closely connected to human disease. This is because LINE elements are greater than $6 \mathrm{~kb}$ in length and support amplification of other retroelements by reverse transcriptase. LINE-1-derived diseases are caused by insertion, element-mediated elimination, and HR (Ostertag and Kazazian, 2001a; Callinan and Batzer, 2006). Insertion of LINE elements that cause disease are not biased to insertion in exons or introns. Their insertion induces atypical transcripts resulting in disease, but the diseases are mostly not fatal. The F9 gene encoding coagulation factor IX is located on $\mathrm{X}$ chromosome and is responsible for hemophilia B (Mukherjee et al., 2004). In other cases, LINE insertion into $A P C$ and $M Y C$ gene can cause colon and breast cancer, respectively (Miki et al., 1992). LINE element-mediated elimination of target-site DNA by retrotransposition can cause critical diseases (Kondo-Iida et al., 1999; Narita et al., 1993; Miné et al., 2007). Very few of these events have been reported. A deletion of 1 base pair in $D M D$ causes Duchenne Muscular Dystrophy (Narita et al., 1993), and a 6-bp deletion in FCMD causes Fukuyama-type congeni-

Table 3. Human genes disrupted by retroelement integration

\begin{tabular}{|c|c|c|c|c|}
\hline Genes & Location & Elements & Diseases & References \\
\hline FKTN & $9 q$ & $\mathrm{~L} 1$ & Fukuyama-type congenital muscular dystophy & $\begin{array}{c}\text { (Narita et al., 1993; Kondo-Iida } \\
\text { et al., 1999) }\end{array}$ \\
\hline DMD & $\mathrm{Xp}$ & L1 & Duchenne Muscular Dystrophy & (Narita et al., 1993) \\
\hline $\mathrm{APC}$ & $5 q$ & L1 & Colon cancer & (Mayer et al., 2005) \\
\hline HBB & $11 p$ & L1 & Beta-thalassemia & (Kimberland et al., 1999) \\
\hline RPS6KA3 & $\mathrm{Xp}$ & $\mathrm{L} 1$ & Coffin-Lowry syndrome & (Martínez-Garay et al., 2003) \\
\hline CYBB & $\mathrm{Xp}$ & L1 & Chronic granulomatous disease & (Meischl et al., 2000) \\
\hline $\mathrm{RP} 2$ & $\mathrm{Xp}$ & $\mathrm{L} 1$ & $\mathrm{X}$-linked retinitis pigmentosa & $\begin{array}{c}\text { (Schwahn et al., 1998; Ostertag } \\
\text { and Kazazian, 2001a) }\end{array}$ \\
\hline F9 & $\mathrm{Xq}$ & L1 & Haemophilia B & (Mukherjee et al., 2004) \\
\hline PDHX & $11 \mathrm{p}$ & L1 & Pyruvate dehydrogenase complex deficiency & (Miné et al., 2007) \\
\hline $\begin{array}{l}\text { EVC, EVC2, C4orf6 } \\
\text { and STK32B }\end{array}$ & $4 \mathrm{p}$ & $\mathrm{L} 1$ & Ellis-van Creveld syndrome & (Temtamy et al., 2008) \\
\hline FAS & $10 q$ & Alu & Autoimmune lymphoproliferative syndrom & (Tighe et al., 2002) \\
\hline F8 & $\mathrm{Xq}$ & Alu & Haemophilia A & (Ganguly et al., 2003) \\
\hline F9 & $\mathrm{Xq}$ & Alu & Haemophilia B & (Vidaud et al., 1993) \\
\hline CASR & $3 q$ & Alu & $\begin{array}{l}\text { Hypocalciuric hypercalcemia and neonatal } \\
\text { severe hyperparathyroidism }\end{array}$ & (Janicic et al., 1995) \\
\hline BRCA2 & $13 q$ & Alu & Breast cancer & (Miki et al., 1996) \\
\hline FGFR2 & $10 \mathrm{q}$ & Alu & Apert syndrome & (Oldridge et al., 1999) \\
\hline GK & $\mathrm{Xp}$ & Alu & Glycerol kinase defiency & (Zhang et al., 2000) \\
\hline OPA1 & $3 q$ & Alu & Autosomal dominant optic atrophy & (Gallus et al., 2010) \\
\hline$\alpha$-galactosidase A & $\mathrm{Xq}$ & Alu & Fabry disease & (Kornreich et al., 1990) \\
\hline HEXB & $5 q$ & Alu & Sandhoff disease & (Neote et al., 1990) \\
\hline
\end{tabular}


tal muscular dystrophy (Kondo-Iida et al., 1999). Further deletion of $P D H X$ located on chromosome 11 results in pyruvate dehydrogenase-complex deficiency (Miné et al., 2007). HR of copies of LINE elements also results in disease; however, this rarely occurs, because they are very critical and rare (Callinan and Batzer, 2006). Disruption of EVC, EVC2, C4orf6, and STK32B by LINE-mediated recombination results in Ellis-van Creveld syndrome, including the abnormal phenotypes of chondrodystrophy, polydactyly, and malformation of the heart (Temtamy et al., 2008; Alves-Pereira et al., 2009). Further studies on retroelements should lead to a better understanding of the many unsolved congenital malformations and genetic diseases.

Alu elements have continuously amplified their 500,000 copies in the primate genome and are involved in approximately $0.1 \%$ of all human genetic diseases. Genetic instability induced by the deletion and duplication of $\mathrm{Alu}$ elements through HR causes various diseases. Numerous studies of $A l u$-derived diseases show that they result from the presence of multiple copies of $A l u$ sequences (Callinan and Batzer, 2006). Insertion of the Alu element in exons and introns creates alternatively spliced transcripts via the formation of new exons or exon skipping, thus disrupting the function of genes, which could result in disease (Andreassen, 2004; Druker and Whitelaw, 2004). However, most $A l u$-derived diseases are caused by $\mathrm{HR}$ between $A l u$ elements. For example, mutations in the well-known BRCA2 is one of the known causes of breast cancer, which occurs through the recombination of $\mathrm{Alu}$ elements in the genic region (Miki et al., 1996). Further, $A l u-A l u$ recombination derived-diseases are biased toward germ-line diseases. Recombination within the genes encoding $\alpha$-galactosidase $\mathrm{A}(G L A)$ and hexosaminidase $\mathrm{B}$ $(H E X B)$ results in Fabry and Sandhoff disease, respectively (Komreich et al., 1990; Neote et al., 1990). Further, Alu elements contribute to segmental duplication and population polymorphism, indicating that these elements play important and specific roles in human disease (Callinan and Batzer, 2006).

HERVs are fossil sequences that originated from an ancient virus infection in the germ line. They contribute to important processes, including speciation, recombination, and oncogenesis, as well as genetic variations and alterations in gene expression that cause diseases in conjunction with other retroelements (Christensen and Møller-Larsen, 2003; Yi et al., 2006). In particular, HERVs exhibit tissue-specific expression directed by their recognition sequences for transcription factors and by cisregulatory elements. These findings implicate a role for HERVs in specific cancers (Romanish et al., 2010). HERVs cause insertional mutation or lead to the creation of antigens that induce autoimmune diseases such as type 1 diabetes, rheumatoid arthritis, and systemic lupus erythematosus (Balada et al., 2009). The impact of HERV-
$\mathrm{W}$ on multiple sclerosis has been extensively documented (Antony et al., 2011). Evidence indicates that multiple sclerosis-related virus (MSRV) pol derived from HERV-W and HERV-K is expressed in the brain tissues of MS patients and is associated with the cause of MS (Johnston et al., 2001; Antony et al., 2011). As described above, HERVs play a role in the development of malignant transformation or tumor growth via the production of HERVencoded oncogenic proteins such as Rec/Np9, and insertional mutation disturb binding of tumor suppressors like P53 and tissue specific expression alteration (Ruprecht et al., 2008; Belancio et al., 2010). HERV-K has been detected in germ cell tumors and in primary or metastatic human melanomas (Gallus et al., 2010). HERV-W proteins have been detected in breast cancers, endometrial carcinomas, and astrocytoma tissues (Bjerregaard et al., 2006; Mameli et al., 2007; Strick et al., 2007). HERV-K is expressed in melanoma cell lines and primary melanoma cells, and HERV-H is expressed at higher levels in colorectal compared with bronchial and cervical cancers (Wentzensen et al., 2007; Serafino et al., 2009). Taken together, these studies indicate that retroelements are responsible for genetic variation and gene regulation through various mechanisms. They are also critical factors in the progression of genetic diseases during hominid radiation.

This work was supported by a grant from the Next Generation BioGreen 21 Program (No. PJ0081062011), Rural Development Administration, Republic of Korea.

\section{REFERENCES}

Ahn, K., and Kim, H.-S. (2009) Structural and quantitative expression analyses of HERV gene family in human tissues. Mol. Cells 28, 99-103.

Alves-Pereira, D., Berini-Aytés, L., and Gay-Escoda, C. (2009) Ellis-van Creveld syndrome. Case report and literature review. Med. Oral Patol. Oral Cir. Bucal 14, E340-E343.

Andreassen, R. (2004) Alu elements in the human genome. Tidsskr. Nor. Laegeforen. 124, 2345-2349.

Antony, J. M., Deslauriers, A. M., Bhat, R. K., Ellestad, K. K., and Power, C. (2011) Human endogenous retroviruses and multiplesclerosis: Innocent bystanders or disease determinants? Biochim. Biophys. Acta 1812, 162-176.

Aravin, A. A., Sachidanandam, R., Girard, A., Fejes-Toth, K., and Hannon, G. J. (2007) Developmentally regulated piRNA clusters implicate MILI in transposon control. Science $\mathbf{3 1 6}$, 744-747.

Aravin, A. A., Sachidanandam, R., Bourc'his, D., Schaefer, C., Pezic, D., Toth, K. F., Bestor, T., and Hannon, G. J. (2008) A piRNA pathway primed by individual transposons is linked to de novo DNA methylation in mice. Mol. Cell 31, 785-799.

Arruda, J. T., Silva, D. M., Silva, C. C., Moura, K. K., and da Cruz, A. D. (2008) Homologous recombination between HERVs causes duplications in the AZFa region of men accidentally exposed to cesium-137 in Goiânia. Genet. Mol. Res. 7, 1063-1069.

Aypar, U., Morgan, W. F., and Baulch, J. E. (2011) Radiation- 
induced epigenetic alterations after low and high LET irradiations. Mutat. Res. 707, 24-33.

Bailey, J. A., Liu, G., and Eichler, E. E. (2003) An Alu transposition model for the origin and expansion of human segmental duplications. Am. J. Hum. Genet. 73, 823-834.

Balada, E., Ordi-Ros, J., and Vilardell-Tarrés, M. (2009) Molecular mechanisms mediated by human endogenous retroviruses (HERVs) in autoimmunity. Rev. Med. Virol. 19, 273-286.

Banerjee, G., Gupta, N., Tiwari, J., and Raman, G. (2005) Ultraviolet-induced transformation of keratinocytes: possible involvement of long interspersed element-1 reverse transcriptase. Photodermatol. Photoimmunol. Photomed. 21, 32-39.

Bartel, D. P. (2004) MicroRNAs: genomics, biogenesis, mechanism, and function. Cell 116, 281-297.

Belancio, V. P., Roy-Engel, A. M., and Deininger, P. L. (2010) All y'all need to know 'bout retroelements in cancer. Semin. Cancer Biol. 20, 200-210.

Belgnaoui, S. M., Gosden, R. G., Semmes, O. J., and Haoudi, A. (2006) Human LINE-1 retrotransposon induces DNA damage and apoptosis in cancer cells. Cancer Cell Int. 6, 13.

Biémont, C., and Vieira, C. (2006) Genetics: junk DNA as an evolutionary force. Nature 443, 521-524.

Bird, A. (2002) DNA methylation patterns and epigenetic memory. Genes Dev. 16, 6-21.

Bjerregaard, B., Holck, S., Christensen, I. J., and Larsson, L. I. (2006) Syncytin is involved in breast cancer-endothelial cell fusions. Cell. Mol. Life Sci. 63, 1906-1911.

Bourc'his, D., and Bestor, T. H. (2004) Meiotic catastrophe and retrotransposon reactivation in male germ cells lacking Dnmt3L. Nature 431, 96-99.

Brennecke, J., Aravin, A. A., Stark, A., Dus, M., Kellis, M., Sachidanandam, R., and Hannon, G. J. (2007) Discrete small RNA-generating loci as master regulators of transposon activity in Drosophila. Cell 128, 1089-1103.

Britten, R. J. (2006) Transposable elements have contributed to thousands of human proteins. Proc. Natl. Acad. Sci. USA 103, 1798-1803.

Brunmeir, R., Lagger, S., Simboeck, E., Sawicka, A., Egger, G., Hagelkruys, A., Zhang, Y., Matthias, P., Miller, W. J., and Seiser, C. (2010) Epigenetic regulation of a murine retrotransposon by a dual histone modification mark. PLoS Genet. 6, e1000927.

Callinan, P. A., and Batzer, M. A. (2006) Retrotransposable elements and human disease. Genome Dyn. 1, 104-115.

Carabana, J., Watanabe, A., Hao, B., and Krangel, M. S. (2011) A barrier-type insulator forms a boundary between active and inactive chromatin at the murine TCR $\beta$ locus. J. Immunol. 186, 3556-3562.

Christensen, T., and Møller-Larsen, A. (2003) Human endogenous retroviruses and disease? Ugeskr. Laeger 165, 556561.

Cohen, C. J., Lock, W. M., and Mager, D. L. (2009) Endogenous retroviral LTRs as promoters for human genes: a critical assessment. Gene 448, 105-114.

Cohen, C. J., Rebollo, R., Babovic, S., Dai, E. L., Robinson, W. P., and Mager, D. L. (2011) Placenta-specific expression of the interleukin-2 (IL-2) receptor $\beta$ subunit from an endogenous retroviral promoter. J. Biol. Chem. 286, 35543-35552.

Cordaux, R., and Batzer, M. A. (2009) The impact of retrotransposons on human genome evolution. Nat. Rev. Genet. 10, 691-703.

Cruickshanks, H. A., and Tufarelli, C. (2009) Isolation of cancerspecific chimeric transcripts induced by hypomethylation of the LINE-1 antisense promoter. Genomics 94, 397-406.
Daskalova, E., Baev, V., Rusinov, V., and Minkov, I. (2007) 3'UTR-located ALU elements: donors of potential miRNA target sites and mediators of network miRNA-based regulatory interactions. Evol. Bioinform. Online 2, 103-120.

De Fazio, S., Bartonicek, N., Di Giacomo, M., Abreu-Goodger, C., Sankar, A., Funaya, C., Antony, C., Moreira, P. N., Enright, A. J., and O'Carroll, D. (2011) The endonuclease activity of Mili fuels piRNA amplification that silences LINE1 elements. Nature 480, 259-263.

Deininger, P. L., and Batzer, M. A. (1999) Alu repeats and human disease. Mol. Genet. Metab. 67, 183-193.

Druker, R., and Whitelaw, E. (2004) Retrotransposon-derived elements in the mammalian genome: a potential source of disease. J. Inherit. Metab. Dis. 27, 319-330.

Farkash, E. A., Kao, G. D., Horman, S. R., and Prak, E. T. (2006) Gamma radiation increases endonuclease-dependent L1 retrotransposition in a cultured cell assay. Nucleic Acids Res. 34, 1196-1204.

Faure, E., Emanoil-Ravier, R., and Champion, S. (1996) UVB irradiation-induced transcription from the long terminal repeat of intracisternal A particles and UVB-induced secretion of an extracellular factor that induces transcription of the intracisternal A particles in unirradiated cells. J. Photochem. Photobiol. B 36, 61-66.

Gallus, G. N., Cardaioli, E., Rufa, A., Da Pozzo, P., Bianchi, S., D’Eramo, C., Collura, M., Tumino, M., Pavone, L., and Federico, A. (2010) Alu-element insertion in an OPA1 intron sequence associated with autosomal dominant optic atrophy. Mol. Vis. 16, 178-183.

Ganguly, A., Dunbar, T., Chen, P., Godmilow, L., and Ganguly, T. (2003) Exon skipping caused by an intronic insertion of a young Alu Yb9 element leads to severe hemophilia A. Hum. Genet. 113, 348-352.

Goetz, W., Morgan, M. N., and Baulch, J. E. (2011) The effect of radiation quality on genomic DNA methylation profiles in irradiated human cell lines. Radiat. Res. 175, 575-587.

Goodier, J. L., and Kazazian, H. H. Jr. (2008) Retrotransposons revisited: the restraint and rehabilitation of parasites. Cell 135, 23-35.

Gunawardane, L. S., Saito, K., Nishida, K. M., Miyoshi, K., Kawamura, Y., Nagami, T., Siomi, H., and Siomi, M. C. (2007) A slicer-mediated mechanism for repeat-associated siRNA $5^{\prime}$ end formation in Drosophila. Science 315, 15871590.

Ha, H.-S., Huh, J.-W., Gim, J.-A., Han, K., and Kim, H.-S. (2011) Transcriptional variations mediated by an alternative promoter of the FPR3 gene. Mamm. Genome 22, 621-633.

Han, K., Lee, J., Meyer, T. J., Wang, J., Sen, S. K., Srikanta, D., Liang, P., and Batzer, M. A. (2007) Alu recombinationmediated structural deletions in the chimpanzee genome. PLoS Genet. 3, 1939-1949.

Hedges, D. J., and Deininger, P. L. (2006) Invitinginstability: Transposable elements, double-strand breaks, and the maintenance of genomeintegrity. Mutat. Res. 616, 46-59.

Hoeijmaker, J. H. (2001) Genome maintenance mechanisms for preventing cancer. Nature 411, 366-374.

Hohenadl, C., Germaier, H., Walchner, M., Hagenhofer, M., Herrmann, M., Stürzl, M., Kind, P., Hehlmann, R., Erfle, V., and Leib-Mösch, C. (1999) Transcriptional activation of endogenous retroviral sequences in human epidermal keratinocytes by UVB irradiation. J. Invest. Dermatol. 113, 587-594.

Hong, K.-W., Shin, Y.-B., Jin, H.-S., Lim, J.-E., Choi, J.-Y., Chang, K.-T., Kim, H.-S., and Oh, B. (2011) Alternative splicing of human height-related zinc finger and BTB domain- 
containing 38 gene through Alu exonization. Biochem. Genet. 49, 283-291.

Huda, A., Bowen, N. J., Conley, A. B., and Jordan, I. K. (2011) Epigenetic regulation of transposable element derived human gene promoters. Gene 475, 39-48.

Hughes, J. F., and Coffin, J. M. (2001) Evidence for genomic rearrangements mediated by human endogenous retroviruses during primate evolution. Nat. Genet. 29, 487-489.

Hughes, J. F., and Coffin, J. M. (2004) Human endogenous retrovirus $\mathrm{K}$ solo-LTR formation and insertional polymorphisms: implications for human and viral evolution. Proc. Natl. Acad. Sci. USA 101, 1668-1672.

Huh, J. W., Kim, D. S., Kang, D. W., Ha, H. S., Ahn, K., Noh, Y. N., Min, D. S., Chang, K. T., and Kim, H. S. (2008) Transcriptional regulation of GSDML gene by antisenseoriented HERV-H LTR element. Arch. Virol. 153, 12011205.

Hutchinson, G. B., Andrew, S. E., McDonald, H., Goldberg, Y. P., Graham, R., Rommens, J. M., and Hayden, M. R. (1993) An Alu element retroposition in two families with Huntington disease defines a new active Alu subfamily. Nucleic Acids Res. 21, 3379-3383.

Hutvágner, G., and Zamore, P. D. (2002) A microRNA in a multiple-turnover RNAi enzyme complex. Science 297, 20562060.

Ichiyanagi, K., Li, Y., Watanabe, T., Ichiyanagi, T., Fukuda, K., Kitayama, J., Yamamoto, Y., Kuramochi-Miyagawa, S., Nakano, T., Yabuta, Y., et al. (2011) Locus- and domaindependent control of DNA methylation at mouse B1 retrotransposons during male germ cell development. Genome Res. 21, 2058-2066.

Illarionova, A. E., Vinogradova, T. V., and Sverdlov, E. D. (2007) Only those genes of the KIAA1245 gene subfamily that contain $\operatorname{HERV}(\mathrm{K})$ LTRs in their introns are transcriptionally active. Virology 358, 39-47.

Jackson, S. P. (2002) Sensing and repairing DNA double-strand breaks. Carcinogenesis 23, 687-696.

Janicic, N., Pausova, Z., Cole, D. E., and Hendy, G. N. (1995) Insertion of an Alu sequence in the $\mathrm{Ca}(2+)$-sensing receptor gene in familial hypocalciuric hypercalcemia and neonatal severe hyperparathyroidism. Am. J. Hum. Genet. 56, 880886.

Johnston, J. B., Silva, C., Holden, J., Warren, K. G., Clark, A. W., and Power, C. (2001) Monocyte activation and differentiation augment human endogenous retrovirus expression: implications for inflammatory brain diseases. Ann. Neurol. 50, 434-442.

Kano, H., Kurahashi, H., and Toda, T. (2007) Genetically regulated epigenetic transcriptional activation of retrotransposon insertion confers mouse dactylaplasia phenotype. Proc. Natl. Acad. Sci. USA 104, 19034-19039.

Karimi, M. M., Goyal, P., Maksakova, I. A., Bilenky, M., Leung, D., Tang, J. X., Shinkai, Y., Mager, D. L., Jones, S., Hirst, M., et al. (2011) DNA methylation and SETDB1/H3K9me3 regulate predominantly distinct sets of genes, retroelements, and chimeric transcripts in mESCs. Cell Stem Cell 8, 676-687.

Kass, D. H., Batzer, M. A., and Deininge, P. L. (1995) Gene conversion as a secondary mechanism of short interspersed element (SINE) evolution. Mol. Cell. Biol. 15, 19-25.

Kazazian, H. H. Jr. (2004) Mobile elements: drivers of genome evolution. Science 303, 1626-1632.

Kim, D.-S., Kim, T.-H., Huh, J.-W., Kim, I.-C., Kim, S.-W., Park, H.-S., and Kim, H.-S. (2006) LINE FUSION GENES: a database of LINE expression in human genes. BMC Genomics
7, 139.

Kim, D.-S., Huh, J.-W., Kim, Y.-H., Park, S.-J., and Chang, K.-T. (2010) Functional impact of transposable elements using bioinformatic analysis and a comparative genomic approach. Mol. Cells 30, 77-87.

Kim, T.-H., Jeon, Y.-J., Kim, W.-Y., and Kim, H.-S. (2005) HESAS: HERVs Expression and Structure Analysis System. Bioinformatics 21, 1699-1700.

Kimberland, M. L., Divoky, V., Prchal, J., Schwahn, U., Berger, W., and Kazazian, H. H. Jr. (1999) Full-length human L1 insertions retain the capacity for high frequency retrotransposition in cultured cells. Hum. Mol. Genet. 8, 1557-1560.

Kochanek, S., Renz, D., and Doerfler, W. (1995) Transcriptional silencing of human Alu sequences and inhibition of protein binding in the box $\mathrm{B}$ regulatory elements by $5^{\prime}-\mathrm{CG}-3^{\prime}$ methylation. FEBS Lett. 360, 115-120.

Kolomietz, E., Meyn, M. S., Pandita, A., and Squire, J. A. (2002) The role of $A l u$ repeat clusters as mediators of recurrent chromosomal aberrations in tumors. Genes Chromosomes Cancer 35, 97-112.

Kondo-Iida, E., Kobayashi, K., Watanabe, M., Sasaki, J., Kumagai, T., Koide, H., Saito, K., Osawa, M., Nakamura, Y., and Toda, T. (1999) Novel mutations and genotypephenotype relationships in 107 families with Fukuyamatype congenital muscular dystrophy (FCMD). Hum. Mol. Genet. 8, 2303-2309.

Kornreich, R., Bishop, D. F., and Desnick, R. J. (1990) Alphagalactosidase A gene rearrangements causing Fabry disease. Identification of short direct repeats at breakpoints in an Alu-rich gene. J. Biol. Chem. 265, 9319-9326.

Kuramochi-Miyagawa, S., Watanabe, T., Gotoh, K., Totoki, Y., Toyoda, A., Ikawa, M., Asada, N., Kojima, K., Yamaguchi, Y., Ijiri, T. W., et al. (2008) DNA methylation of retrotransposon genes is regulated by Piwi family members MILI and MIWI2 in murine fetal testes. Genes Dev. 22, 908-917.

Lee, J., Han, K., Meyer, T. J., Kim, H.-S., and Batzer, M. A. (2008) Chromosomal inversions between human and chimpanzee lineages caused by retrotransposons. PLoS ONE 3, e4047.

Lee, J.-R., Huh, J.-W., Kim, D.-S., Ha, H.-S., Ahn, K., Kim, Y.-J., Chang, K.-T., and Kim, H.-S. (2009a) Lineage specific evolutionary events on SFTPB gene: Alu recombination-mediated deletion (ARMD), exonization, and alternative splicing events. Gene 435, 29-35.

Lee, K.-H., Chen, Y.-L., Yeh, S.-D., Hsiao, M., Lin, J.-T., Goan, Y.-G., and Lu, P.-J. (2009b) MicroRNA-330 acts as tumor suppressor and induces apoptosis of prostate cancer cells through E2F1-mediated suppression of Akt phosphorylation. Oncogene 28, 3360-3370.

Li, J., Akagi, K., Hu, Y., Trivett, A. L., Hlynialuk, C. J., Swing, D. A., Volfovsky, N., Morgan, T. C., Golubeva, Y., Stephens, R. M., et al. (2012) Mouse endogenous retroviruses can trigger premature transcriptional termination at a distance. Genome Res. 22, 870-884.

Liang, Q., Ding, J., Xu, R., Xu, Z., and Zheng, S. (2010) The novel human endogenous retrovirus-related gene, psiTPTE22HERV, is silenced by DNA methylation in cancers. Int. J. Cancer 127, 1833-1843.

Luco, R. F., Allo, M., Schor, I. E., Kornblihtt, A. R., and Misteli, T. (2011) Epigenetics in alternative pre-mRNA splicing. Cell 144, 16-26.

Macaulay, E. C., Weeks, R. J., Andrews, S., and Morison, I. M. (2011) Hypomethylation of functional retrotransposonderived genes in the human placenta. Mamm. Genome 22, $722-735$. 
Macfarlan, T. S., Gifford, W. D., Agarwal, S., Driscoll, S., Lettieri, K., Wang, J., Andrews, S. E., Franco, L., Rosenfeld, M. G., Ren, B., et al. (2011) Endogenous retroviruses and neighboring genes are coordinately repressed by LSD1/KDM1A. Genes Dev. 25, 594-607.

Macfarlan, T. S., Gifford, W. D., Driscoll, S., Lettieri, K., Rowe, H. M., Bonanomi, D., Firth, A., Singer, O., Trono, D., and Pfaff, S. L. (2012) Embryonic stem cell potency fluctuates with endogenous retrovirus activity. Nature 487, 57-63.

Macia, A., Muñoz-Lopez, M., Cortes, J. L., Hastings, R. K., Morell, S., Lucena-Aguilar, G., Marchal, J. A., Badge, R. M., and Garcia-Perez, J. L. (2011) Epigenetic control of retrotransposon expression in human embryonic stem cells. Mol. Cell. Biol. 31, 300-316.

Mager, D. L., Hunter, D. G., Schertzer, M., and Freeman, J. D. (1999) Endogenous retroviruses provide the primary polyadenylation signal for two new human genes (HHLA2 and HHLA3). Genomics 59, 255-263.

Maksakova, I. A., Zhang, Y., and Mager, D. L. (2009) Preferential epigenetic suppression of the autonomous MusD over the nonautonomous ETn mouse retrotransposons. Mol. Cell. Biol. 29, 2456-2468.

Mameli, G., Astone, V., Arru, G., Marconi, S., Lovato, L., Serra, C., Sotgiu, S., Bonetti, B., and Dolei, A. (2007) Brains and peripheral blood mononuclear cells of multiple sclerosis (MS) patients hyperexpress MS-associated retrovirus/HERV-W endogenous retrovirus, but not Human herpesvirus 6 . J. Gen. Virol. 88, 264-274.

Martens, J. H., O'Sullivan, R. J., Braunschweig, U., Opravil, S., Radolf, M., Steinlein, P., and Jenuwein, T. (2005) The profile of repeat-associated histone lysine methylation states in the mouse epigenome. EMBO J. 24, 800-812.

Martínez-Garay, I., Ballesta, M. J., Oltra, S., Orellana, C., Palomeque, A., Moltó, M. D., Prieto, F., and Martínez, F. (2003) Intronic L1 insertion and F268S, novel mutations in RPS6KA3 (RSK2) causing Coffin-Lowry syndrome. Clin. Genet. 64, 491-496.

Mätlik, K., Redik, K., and Speek, M. (2006) L1 antisense promoter drives tissue-specific transcription of human genes. J. Biomed. Biotechnol. 2006, 71753.

Matsui, T., Leung, D., Miyashita, H., Maksakova, I. A., Miyachi, H., Kimura, H., Tachibana, M., Lorincz, M. C., and Shinkai, Y. (2010) Proviral silencing in embryonic stem cells requires the histone methyltransferase ESET. Nature 464, 927931.

Matzke, M., Aufsatz, W., Kanno, T., Daxinger, L., Papp, I., Mette, M. F., and Matzke, A. J. (2004) Genetic analysis of RNA-mediated transcriptional gene silencing. Biochim. Biophys. Acta 1677, 129-141.

Mayer, J., Stuhr, T., Reus, K., Maldener, E., Kitova, M., Asmus, F., and Meese, E. (2005) Haplotype analysis of the human endogenous retrovirus locus HERV-K(HML-2.HOM) and its evolutionary implications. J. Mol. Evol. 61, 706-715.

Medstrand, P., Landry, J.-R., and Mager, D. L. (2001) Long terminal repeats are used as alternative promoters for the endothelin B receptor and apolipoprotein C-I genes in humans. J. Biol. Chem. 276, 1896-1903.

Meischl, C., Boer, M.d., Åhlin, A., and Roos, D. (2000) A new exon created by intronic insertion of a rearranged LINE-1 element as the cause of chronic granulomatous disease. Eur. J. Hum. Genet. 8, 697-703.

Miki, Y., Nishisho, I., Horii, A., Miyoshi, Y., Utsunomiya, J., Kinzler, K. W., Vogelstein, B., and Nakamura, Y. (1992) Disruption of the $A P C$ gene by a retrotransposal insertion of L1 sequence in a colon cancer. Cancer Res. 52, 643-645.
Miki, Y., Katagiri, T., Kasumi, F., Yoshimoto, T., and Nakamura, Y. (1996) Mutation analysis in the BRCA2 gene in primary breast cancers. Nat. Genet. 13, 245-247.

Miné, M., Chen, J.-M., Brivet, M., Desguerre, I., Marchant, D., de Lonlay, P., Bernard, A., Férec, C., Abitbol, M., Ricquier, D., et al. (2007) A large genomic deletion in the PDHX gene caused by the retrotranspositional insertion of a full-length LINE-1 element. Hum. Mutat. 28, 137-142.

Montoya-Durango, D. E., Liu, Y., Teneng, I., Kalbfleisch, T., Lacy, M. E., Steffen, M. C., and Ramos, K. S. (2009) Epigenetic control of mammalian LINE-1 retrotransposon by retinoblastoma proteins. Mutat. Res. 665, 20-28.

Morales, J. F., Snow, E. T., and Murnane, J. P. (2003) Environmental factors affecting transcription of the human L1 retrotransposon. II. Stressors. Mutagenesis 18, 151158.

Moran, J. V., DeBerardinis, R. J., and Kazazian, H. H. Jr. (1999) Exon shuffling by L1 retrotransposition. Science $\mathbf{2 8 3}$, 1530-1534.

Mukherjee, S., Mukhopadhyay, A., Banerjee, D., Chandak, G. R., and Ray, K. (2004) Molecular pathology of haemophilia $\mathrm{B}$ : identification of five novel mutations including a LINE 1 insertion in Indian patients. Haemophilia 10, 259-263.

Narita, N., Nishio, H., Kitoh, Y., Ishikawa, Y., Ishikawa, Y., Minami, R., Nakamura, H., and Matsuo, M. (1993) Insertion of a $5^{\prime}$ truncated L1 element into the $3^{\prime}$ end of exon 44 of the dystrophin gene resulted in skipping of the exon during splicing in a case of Duchenne muscular dystrophy. J. Clin. Invest. 91, 1862-1867.

Nelson, P. N., Lever, A. M., Smith, S., Pitman, R., Murray, P., Perera, S. A., Westwood, O. M., Hay, F. C., Ejtehadi, H. D., and Booth, J. C. (1999) Molecular investigations implicate human endogenous retroviruses as mediators of antiretroviral antibodies in autoimmune rheumatic disease. Immunol. Invest. 28, 277-289.

Neote, K., McInnes, B., Mahuran, D. J., and Gravel, R. A. (1990) Structure and distribution of an Alu-type deletion mutation in Sandhoff disease. J. Clin. Invest. 86, 1524-1531.

Norris, J., Fan, D., Aleman, C., Marks, J. R., Futreal, P. A., Wiseman, R. W., Iglehart, J. D., Deininger, P. L., and McDonnell, D. P. (1995) Identification of a new subclass of $A l u$ DNA repeats which can function as estrogen receptordependent transcriptional enhancers. J. Biol. Chem. 270, 22777-22782.

Ohnishi, Y., Totoki, Y., Toyoda, A., Watanabe, T., Yamamoto, Y., Tokunaga, K., Sakaki, Y., Sasaki, H., and Hohjoh, H. (2012) Active role of small non-coding RNAs derived from SINE/B1 retrotransposon during early mouse development. Mol. Biol. Rep. 39, 903-909.

Oldridge, M., Zackai, E. H., McDonald-McGinn, D. M., Iseki, S., Morriss-Kay, G. M., Twigg, S. R., Johnson, D., Wall, S. A., Jiang, W., Theda, C., et al. (1999) De novo Alu-element insertions in FGFR2 identify a distinct pathological basis for apert syndrome. Am. J. Hum. Genet. 64, 446-461.

Onno, M., Nakamura, T., Hillova, J., and Hill, M. (1992) Rearrangement of the human tre oncogene by homologous recombination between Alu repeats of nucleotide sequences from two different chromosomes. Oncogene 7, 2519-2523.

Ostertag, E. M., and Kazazian, H. H. Jr. (2001a) Biology of mammalian L1 retrotransposons. Annu. Rev. Genet. 35, 501-538.

Ostertag, E. M., and Kazazian, H. H. Jr. (2001b) Twin priming: a proposed mechanism for the creation of inversions in L1 retrotransposition. Genome Res. 11, 2059-2065.

Pauler, F. M., Sloane, M. A., Huang, R., Regha, K., Koerner, M. 
V., Tamir, I., Sommer, A., Aszodi, A., Jenuwein, T., and Barlow, D. P. (2009) H3K27me3 forms BLOCs over silent genes and intergenic regions and specifies a histone banding pattern on a mouse autosomal chromosome. Genome Res. 19, 221-233.

Pélisson, A., Sarot, E., Payen-Groschêne, G., and Bucheton, A. (2007) A novel repeat-associated small interfering RNAmediated silencing pathway downregulates complementary sense gypsy transcripts in somatic cells of the Drosophila ovary. J. Virol. 81, 1951-1960.

Piriyapongsa, J., Mariño-Ramírez, L., and Jordan, I. K. (2007) Origin and evolution of human microRNAs from transposable elements. Genetics 176, 1323-1337.

Reiche, J., Pauli, G., and Ellerbro, H. (2010) Differential expression of human endogenous retrovirus $\mathrm{K}$ transcripts in primary human melanocytes and melanoma cell lines after UV irradiation. Melanoma Res. 20, 435-440.

Reiss, D., Zhang, Y., and Mager, D. L. (2007) Widely variable endogenous retroviral methylation levels in human placenta. Nucleic Acids Res. 35, 4743-4754.

Richards, K. L., Zhang, B., Baggerly, K. A., Colella, S., Lang, J. C., Schuller, D. E., and Krahe, R. (2009) Genome-wide hypomethylation in head and neck cancer is more pronounced in HPV-negative tumors and is associated with genomic instability. PLoS ONE 4, e4941.

Romanish, M. T., Cohen, C. J., and Mager, D. L. (2010) Potential mechanisms of endogenous retroviral-mediated genomic instability in human cancer. Semin. Cancer Biol. 20, 246253.

Rowe, H. M., Jakobsson, J., Mesnard, D., Rougemont, J., Reynard, S., Aktas, T., Maillard, P. V., Layard-Liesching, H., Verp, S., Marquis, J., et al. (2010) KAP1 controls endogenous retroviruses in embryonic stem cells. Nature 463, 237-240.

Roy, A. M., Carroll, M. L., Nguyen, S. V., Salem, A.-H., Oldridge, M., Wilkie, A. O., Batzer, M. A., and Deininger, P. L. (2000) Potential gene conversion and source genes for recently integrated Alu elements. Genome Res. 10, 1485-1495.

Ruda, V. M., Akopov, S. B., Trubetskoy, D. O., Manuylov, N. L., Vetchinova, A. S., Zavalova, L. L., Nikolaev, L. G., and Sverdlov, E. D. (2004) Tissue specificity of enhancer and promoter activities of a HERV-K(HML-2) LTR. Virus Res. 104, 11-16.

Ruprecht, K., Ferreira, H., Flockerzi, A., Wahl, S., Sauter, M., Mayer, J., and Mueller-Lantzsch, N. (2008) Human endogenous retrovirus family HERV-K(HML-2) RNA transcripts are selectively packaged into retroviral particles produced by the human germ cell tumor line Tera-1 and originate mainly from a provirus on chromosome $22 q 11.21$. J. Virol. 82, 10008-10016.

Schön, U., Seifarth, W., Baust, C., Hohenadl, C., Erfle, V., and Leib-Mösch, C. (2001) Cell type-specific expression and promoter activity of human endogenous retroviral long terminal repeats. Virology 279, 280-291.

Schulte, A. M., Malerczyk, C., Cabal-Manzano, R., Gajarsa, J. J., List, H.-J., Riegel, A. T., and Wellstein, A. (2000) Influence of the human endogenous retrovirus-like element HERVE.PTN on the expression of growth factor pleiotrophin: a critical role of a retroviral Sp1-binding site. Oncogene 19, 3988-3998.

Schulz, W. A., Steinhoff, C., and Florl, A. R. (2006) Methylation of endogenous human retroelements in health and disease. Curr. Top. Microbiol. Immunol. 310, 211-250.

Schwahn, U., Lenzner, S., Dong, J., Feil, S., Hinzmann, B., van Duijnhoven, G., Kirschner, R., Hemberger, M., Bergen, A. A., Rosenberg, T., et al. (1998) Positional cloning of the gene for X-linked retinitis pigmentosa 2. Nat. Genet. 19, 327332 .

Sen, S. K., Han, K., Wang, J., Lee, J., Wang, H., Callinan, P. A., Dyer, M., Cordaux, R., Liang, P., and Batzer, M. A. (2006) Human genomic deletions mediated by recombination between Alu elements. Am. J. Hum. Genet. 79, 41-53.

Serafino, A., Balestrieri, E., Pierimarchi, P., Matteucci, C., Moroni, G., Oricchio, E., Rasi, G., Mastino, A., Spadafora, C., Garaci, E., et al. (2009) The activation of human endogenous retrovirus $\mathrm{K}$ (HERV-K) is implicated in melanoma cell malignant transformation. Exp. Cell Res. 315, 849862.

Sharan, C., Hamilton, N. M., Parl, A. K., Singh, P. K., and Chaudhuri, G. (1999) Identification and characterization of a transcriptional silencer upstream of the human BRCA2 gene. Biochem. Biophys. Res. Commun. 265, 285-290.

Sin, H.-S., Huh, J.-W., Kim, D.-S., Kim, T.-H., Ha, H.-S., Kim, W.-Y., Park, H.-K., Kim, C.-M., and Kim, H.-S. (2006) Endogenous retrovirus-related sequences provide an alternative transcript of $M C J$ genes in human tissues and cancer cells. Genes Genet. Syst. 81, 333-339.

Slotkin, R. K., and Martienssen, R. (2007) Transposable elements and the epigenetic regulation of the genome. Nat. Rev. Genet. 8, 272-285.

Smalheiser, N. R., and Torvik, V. I. (2005) Mammalian microRNAs derived from genomic repeats. Trends Genet. 21, 322-326.

Steinhoff, C., and Schulz, W. A. (2003) Transcriptional regulation of the human LINE-1 retrotransposon L1.2B. Mol. Genet. Genomics 270, 394-402.

Stengel, S., Fiebig, U., Kurth, R., and Denner, J. (2010) Regulation of human endogenous retrovirus- $\mathrm{K}$ expression in melanomas by $\mathrm{CpG}$ methylation. Genes Chromosomes Cancer 49, 401-411.

Strick, R., Ackermann, S., Langbein, M., Swiatek, J., Schubert, S. W., Hashemolhosseini, S., Koscheck, T., Fasching, P. A., Schild, R. L., Beckmann, M. W., et al. (2007) Proliferation and cell-cell fusion of endometrial carcinoma are induced by the human endogenous retroviral Syncytin- 1 and regulated by TGF- $\beta$. J. Mol. Med. 85, 23-38.

Sun, C., Skaletsky, H., Rozen, S., Gromoll, J., Nieschlag, E., Oates, R., and Page, D. C. (2000) Deletion of azoospermia factor a $(\mathrm{AZFa})$ region of human $\mathrm{Y}$ chromosome caused by recombination between HERV15 proviruses. Hum. Mol. Genet. 9, 2291-2296.

Suzuki, M. M., and Bird, A. (2008) DNA methylation landscapes: provocative insights from epigenomics. Nat. Rev. Genet. 9, $465-476$.

Sverdlov, E. D. (2000) Retroviruses and primate evolution. Bioessays 22, 161-171.

Tanaka, I., and Ishihara, H. (1995) Unusual long target duplication by insertion of intracisternal A-particle element in radiation-induced acute myeloid leukemia cells in mouse. FEBS Lett. 376, 146-150.

Temtamy, S. A., Aglan, M. S., Valencia, M., Cocchi, G., Pacheco, M., Ashour, A. M., Amr, K. S., Helmy, S. M., El-Gammal, M. A., Wright, M., et al. (2008) Long interspersed nuclear element-1 (LINE1)-mediated deletion of EVC, EVC2, C4orf6, and $S T K 32 B$ in Ellis - van Creveld syndrome with borderline intelligence. Hum. Mutat. 29, 931-938.

Teneng, I., Montoya-Durango, D. E., Quertermous, J. L., Lacy, M. E., and Ramos, K. S. (2011) Reactivation of L1 retrotransposon by benzo(a)pyrene involves complex genetic and epigenetic regulation. Epigenetics 6, 355-367.

Tighe, P. J., Stevens, S. E., Dempsey, S., Le Deist, F., Rieux- 
Lauca, F., and Edgar, J. D. (2002) Inactivation of the Fas gene by Alu insertion: retrotransposition in an intron causing splicing variation and autoimmune lymphoproliferative syndrome. Genes Immun. 3, S66-S70.

Vagin, V. V., Sigova, A., Li, C., Seitz, H., Gvozdev, V., and Zamore, P. D. (2006) A distinct small RNA pathway silences selfish genetic elements in the germline. Science 313, 320 324.

Vidaud, D., Vidaud, M., Bahnak, B. R., Siguret, V., Gispert Sanchez, S., Laurian, Y., Meyer, D., Goossens, M., and Lavergne, J. M. (1993) Haemophilia B due to a de novo insertion of a human-specific Alu subfamily member within the coding region of the factor IX gene. Eur. J. Hum. Genet. 1, 30-36.

Walsh, C. P., Chaillet, J. R., and Bestor, T. H. (1998) Transcription of IAP endogenous retroviruses is constrained by cytosine methylation. Nat. Genet. 20, 116-117.

Walsh, T., Casadei, S., Coats, K. H., Swisher, E., Stray, S. M., Higgins, J., Roach, K. C., Mandell, J., Lee, M. K., Ciernikova, S., et al. (2006) Spectrum of mutations in BRCA1, BRCA2, CHEK2, and TP53 in families at high risk of breast cancer. JAMA 295, 1379-1388.

Wang-Johanning, F., Frost, A. R., Jian, B., Azuero, R., Lu, D. W., Chen, D.-T., and Johanning, G. L. (2003) Detecting the expression of human endogenous retrovirus $\mathrm{E}$ envelope transcripts in human prostate adenocarcinoma. Cancer $\mathbf{9 8}$,
187-197.

Weinstock, D. M., Richardson, C. A., Elliott, B., and Jasin, M. (2006) Modeling oncogenic translocations: Distinct roles for double-strand break repair pathways in translocation formation in mammalian cells. DNA Repair 5, 1065-1074.

Wentzensen, N., Coy, J. F., Knaebel, H.-P., Linnebacher, M., Wilz, B., Gebert, J., von Knebel and Doeberitz, M. (2007) Expression of an endogenous retroviral sequence from the HERV-H group in gastrointestinal cancers. Int. J. Cancer 121, 1417-1423.

Yi, J.-M., Kim, H.-M., and Kim, H.-S. (2006) Human endogenous retrovirus HERV-H family in human tissues and cancer cells: expression, identification, and phylogeny. Cancer Lett. 231, 228-239.

Yoder, J. A., Walsh, C. P., and Bestor, T. H. (1997) Cytosine methylation and the ecology of intragenomic parasites. Trends Genet. 13, 335-340.

Yulug, I. G., Yulug, A., and Fisher, E. M. (1995) The frequency and position of Alu repeats in cDNAs, as determined by database searching. Genomics 27, 544-548.

Zhang, Y., Dipple, K. M., Vilain, E., Huang, B. L., Finlayson, G., Therrell, B. L., Worley, K., Deininger, P., and McCabe, E. R. (2000) AluY insertion (IVS4-52ins316alu) in the glycerol kinase gene from an individual with benign glycerol kinase deficiency. Hum. Mutat. 15, 316-323. 